\title{
AiMT
}

Advances in Military Technology

Vol. 12, No. 1 (2017), pp. 113-128

ISSN 1802-2308, eISSN 2533-4123

DOI 10.3849/aimt.01172

\section{Assessment of Selected Cannons according to the Probability of Target Destruction}

\author{
J. Němeček ${ }^{*}$ and M. Polášek \\ Department of Aircraft Electrical Systems, University of Defence, Czech Republic
}

The manuscript was received on 4 January 2017 and was accepted after revision for publication on 19 June 2017.

\begin{abstract}
:
The article discribes combat effectiveness of aircraft automatic cannons and compares combat effectiveness of M61A1 rotary cannon with cannons being used on aircraft of the Czech Air Force. The procedure and examples of probability calculation for aerial target destruction are presented for hight rate of fire weapons firing one burst. The procedure is shown for a step law and an exponential law of target destruction and for the constant and changing target hit probability. Basic characteristics for all types of rapid-firing cannons which are part of standard armament of modern aircraft are included in this paper.
\end{abstract}

\section{Keywords:}

aircraft automatic cannon, rate of fire, probability of target hits, law of destruction

\section{Introduction}

Aircraft automatic weapons, machine guns and cannons are a standard part of an armament of modern fighters. They are designed for destruction of aerial and ground targets at a short distance. Required destructive effects of the projectiles are given by the target vulnerability, and therefore, each weapon has a wide range of ammunition, covering different cartridges with destructive effects, such as armour piercing, high explosive, fragmentation, and incendiary effects $[1,2]$. Basic types of the aircraft automatic highrate fire cannons are: revolver, rotary, and twin-barrel cannons.

If we want to assess combat effectiveness (performance) of the aircraft automatic cannons (AAC) for the aerial target destruction, the following parameters of the AAC and ammunition have to be taken into consideration: calibre, rate of fire, and mass of the explosive charge of the projectile.

The total mass of the projectiles impacting the target at a certain length of burst depends on the above-mentioned parameters. If firing at an aerial target, it is assumed that the destructive effect is given by the total mass of the explosive material in the

\footnotetext{
* Corresponding author: Department of Aircraft Electrical Systems, Faculty of Military Technology, University of Defence, Kounicova 65, 66210 Brno, Czech Republic.

Phone: +4209734451 98, Fax:+4209734427 15, E-mail: jiri.nemecek@unob.cz
} 
target. In addition, the capability to destroy the target depends also on the probability of the target hits. According to the target hit probability and the ammunition destructive effect, we can express combat effectiveness of the particular weapon by its target destruction probability.

Due to the fact that the Czech Air Force aircraft are equipped with the twin-barrel and revolver cannons and foreign aircraft have rotary cannons, a question arises as what is the target destruction probability for each cannon. Target destruction probability is one of the main criteria for selecting a cannon for the particular fighter. This paper presents calculation procedures of the target destruction probability including a comparison of four different types of high-rate of fire cannons. Performance of the selected cannons is assessed based on the target vulnerability and on the given weapon attributes. Pilot factor, gunsight and firing-post influence on the probability of the target destruction are not taken into consideration in this article. They are not relevant for the provided analysis, as their importance for the combat effectiveness changes and depends on the individual properties of the specific aircraft and the pilot. The aim of the analysis is to evaluate performance of the cannons themselves.

\section{Rate of Fire}

The weapon rate of fire is given by the following general formula [1]

$$
k=\frac{1}{t_{\mathrm{s}}}
$$

where $t_{\mathrm{s}}-$ the interval between two consecutive shots.

For a classical weapon (one barrel, one chamber), the interval between two consecutive shots $t_{\mathrm{cl}}$ is given by the following formula

$$
t_{\mathrm{cl}}=t_{\mathrm{s}}=t_{1 \mathrm{c}},
$$

where $t_{1 \mathrm{c}}$ - the duration of one functional cycle.

Then, a classical weapon rate of fire $k_{\mathrm{cl}}$ is

$$
k_{\mathrm{cl}}=\frac{1}{t_{\mathrm{cl}}} \text {. }
$$

Rate of fire of classical weapon can be increased by shortening its functional cycle. For high rate of fire weapon, the following formula applies

$$
t_{\mathrm{s}}<t_{1 \mathrm{c}} \text {. }
$$

Revolver AAC rate of fire depends commonly on the number of barrels and chambers. We consider the weapon with one barrel and five chambers. For such weapon, the rate of fire $k_{\mathrm{R}}$ is given by the following formula [1]

$$
k_{\mathrm{R}} \approx 1.8 k_{\mathrm{cl}} \text {. }
$$

Rotary AAC nominal (maximum) rate of fire $k_{\mathrm{G}}$ is given by the following formula [1]

$$
k_{\mathrm{G}}=i_{\mathrm{b}} k_{\mathrm{cl}} \text {, }
$$

where $i_{\mathrm{b}}-$ the number of barrels.

For every weapon, this rate of fire matches a certain nominal angular velocity of the barrel block revolution. 
Twin-barrel AAC rate of fire $k_{\mathrm{T}}$ is given by the following formula [1]

$$
k_{\mathrm{T}}=2 k_{\mathrm{cl}} \text {. }
$$

However, in real life, the rate of AAC of this type is bigger.

Revolver and twin-barrel weapons reach the nominal rate of fire immediately after the firing begins. The rotary weapon rate of fire gradually rises during the initial firing period and the nominal rate of fire is reached after certain time. After that, the rate of fire is constant $[1,3]$. It results from the fact that the barrel block is affected by the inertial forces that have to be exceeded during the acceleration to the nominal speed of revolution. The spin up time is in the order of tenths of seconds. If we use a simplifying assumption that the barrel block spins with a constant angular acceleration, then, the time dependence of the rotary weapon rate of fire $k_{\mathrm{G} \leq t \mathrm{a}}$ is given by the formula [1]

$$
k_{\mathrm{G} \leq t \mathrm{a}}=\frac{k_{\mathrm{G}}}{t_{\mathrm{a}}} t,
$$

where $t_{\mathrm{a}}$ - the spin up time; time in which the nominal rate of fire is reached,

$t$ - the time, $t \in\left\langle 0, t_{\mathrm{a}}\right\rangle$.

When $t>t_{\mathrm{a}}$, the rotary weapon rate of fire has nominal value $k_{\mathrm{G}}$.

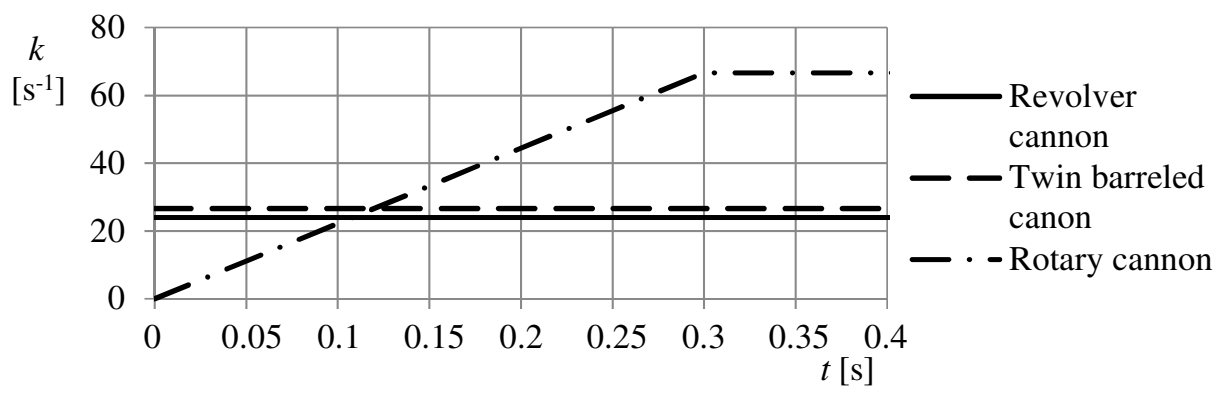

Fig. 1 Time dependence of rate of fire

Time dependences of rate of fire for individual types of AAC are shown in Fig. 1. The graphs are only illustrative and are valid for the following parameters: $k_{\mathrm{cl}}=800 \mathrm{~min}^{-1}, i_{\mathrm{b}}=5, t_{\mathrm{a}}=0.3 \mathrm{~s}$. However, real rotary cannons do not satisfy the simplifying precondition mentioned above. Modelled and measured trends of angular velocities of rotary machine gun with $12.7 \mathrm{~mm}$ calibre are in [3]. The run up of the gun is nonlinear and the transition to the nominal rate of fire is smooth.

\section{Time Dependency of Fired Projectile Number}

The number of projectiles fired by various cannons increases with time in line with increasing rates of fire. For the revolver and twin barrel cannon, we can write:

$$
\begin{gathered}
n_{\mathrm{R}}=k_{\mathrm{R}} t, \\
n_{\mathrm{T}}=k_{\mathrm{T}} t,
\end{gathered}
$$

where $n_{\mathrm{R}}, n_{\mathrm{T}}$ - the number of projectiles fired by the revolver or the twin barrel cannon respectively, at time $t$ from the start of firing. 
For rotary cannons, the problem is a bit more complicated as the fact that the nominal rate of fire is reached with a certain delay has to be considered. The projectile number $n_{\mathrm{G} \leq \mathrm{ta}}$ when $t \leq t_{\mathrm{a}}$ is given by the following general formula

$$
n_{\mathrm{G} \leq t \mathrm{a}}=\int_{0}^{t} k_{\mathrm{G} \leq t \mathrm{a}} \mathrm{d} \tau .
$$

After substituting the right side of ( 8$)$ for $k_{\mathrm{G} \leq \mathrm{ta}}$, the formula is:

$$
n_{\mathrm{G} \leq t \mathrm{a}}=\int_{0}^{t} \frac{k_{\mathrm{G}}}{t_{\mathrm{a}}} \tau \mathrm{d} \tau .
$$

The solution of the integral is:

$$
n_{\mathrm{G} \leq t \mathrm{a}}=\frac{k_{\mathrm{G}}}{2 t_{\mathrm{a}}} t^{2} .
$$

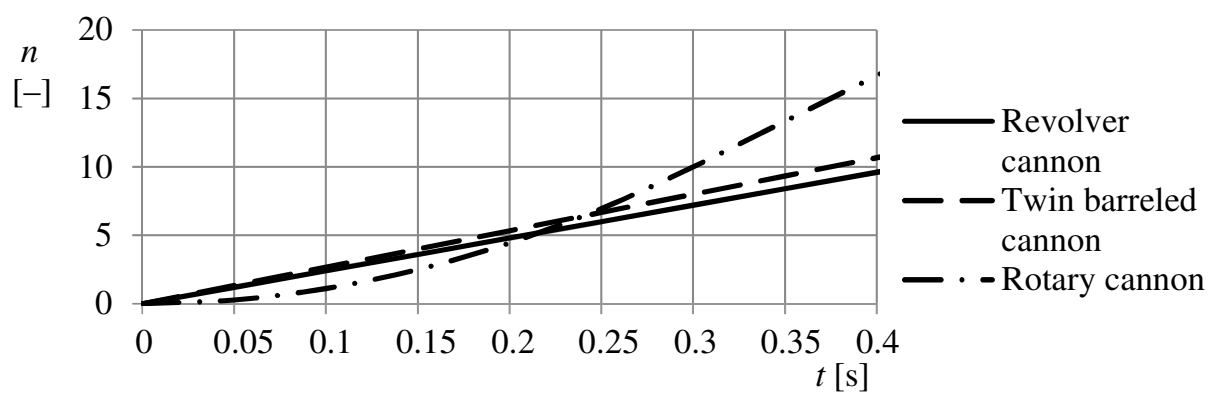

Fig. 2 Time dependence of number of fired projectiles

The number of projectiles when $t>t_{\mathrm{a}}$ can be written as follows:

$$
n_{\mathrm{G}>t \mathrm{a}}=k_{\mathrm{G}}\left(t-\frac{t_{\mathrm{a}}}{2}\right) \text {. }
$$

Time dependences of the fired projectiles for different weapons are depicted in Fig. 2. The individual graphs are again valid for $k_{\mathrm{cl}}=800 \mathrm{~min}^{-1}, i_{\mathrm{b}}=5$ and $t_{\mathrm{a}}=0.3 \mathrm{~s}$.

\section{Target Destruction}

In the following chapters, a target destruction probability is analysed for one burst of fire when every shot in the group of rounds is considered independent [4].

The probability of the target destruction is proportional to both the probability of the target hits $p$ for every single projectile and to the number of projectiles $n$ fired towards the target, as the destruction probability depends on the number of target hits. This probability is namely determined by the type of the target, the ammunition destruction effect and the ammunition calibre which the amount of the released destructive material sent towards the target depends on. Since the real target is a complex object, with different parts having different vulnerability, the individual target destruction probabilities will be different depending on the number of hits for different types of targets and ammunition. 


\subsection{Probability of Target Hit for One Projectile}

Assuming that the positions (impact points) of the projectiles in the dispersion plane follow the normal distribution with the probability density function expressed by the formula $[3,4]$

$$
f(x, y)=\frac{\rho^{2}}{\pi E_{\mathrm{x}} E_{\mathrm{y}}} \cdot \mathrm{e}^{-\rho^{2}\left[\frac{(x-\bar{x})^{2}}{E_{\mathrm{x}}^{2}}+\frac{(y-\bar{y})^{2}}{E_{\mathrm{y}}^{2}}\right],}
$$

where $\bar{x}, \bar{y}$ - the mean values, the systematic errors of fire,

$E_{\mathrm{x}}, E_{\mathrm{y}}-$ the probable errors characterizing dispersion of the projectile impact points in the directions of the individual dispersion axes,

$\rho=0.477$.

Then, we assume that there are no systematic errors (We do not consider the errors of the gunsight.) and both the calculated collision points of the projectile and the target (origin of coordinates) are identical with the centre of the target. The distribution of the impact points is usually centred around this point. If the real aerial target is replaced by a calculated rectangular target, see Fig. 3, the probability of hitting the target can be expressed by [4-6]:

$$
p=\Phi\left(\frac{a}{E_{\mathrm{x}}}\right) \cdot \Phi\left(\frac{b}{E_{\mathrm{y}}}\right),
$$

where $a, b$ - the distances of the target end points from the axis $y$ and $x$ respectively,

$\Phi(\cdot)$ - the modified Laplace function.

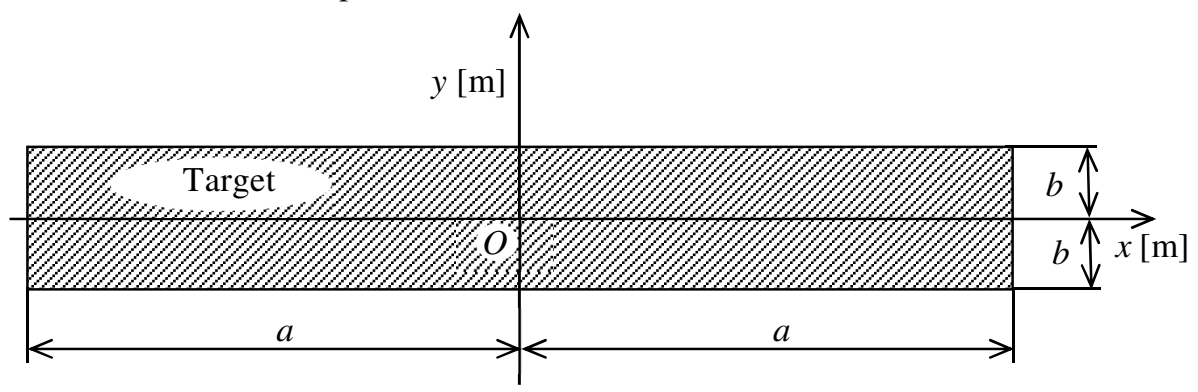

Fig. 3 Rectangular target in the plane of dispersion

The situation in Fig. 3 represents an assault which is led perpendicularly to the target's longitudinal axis in a plane of the target's wings. This example simplifies the real situation as the real size and form of the calculated target significantly changes depending on the mutual position of the fighter and the target. However, this simplification is acceptable, as the aim of this article is to compare different types of cannons under the same conditions.

Values of the modified Laplace function are tabulated [4]. Arguments $a / E_{\mathrm{x}}$ and $b / E_{\mathrm{y}}$ depend on both the size of the specific target and the probable errors of the specific cannon and its ammunition for a certain distance between the fighter and the target. For a medium-sized military aircraft, the values of parameters $a$ and $b$ lie in areas around ten meters and one meter, respectively. If we consider the circularly symmetrical dispersion pattern, we can write: $E=E_{\mathrm{x}}=E_{\mathrm{y}}$. 
For approximate calculation of the hit probability, we can use the following formula $[7,8]$

$$
p=\frac{A_{\mathrm{DPT}}}{A_{\mathrm{DP}}},
$$

where $A_{\mathrm{DP}}$ - the area of the dispersion pattern,

$A_{\mathrm{DPT}}$ - the area of the overlap of the target and the dispersion pattern.

\subsection{Target Destruction Law}

Based on practical experiments, we can determine the number of impacts that are needed to achieve the target destruction with a practical certainty. We assume that the probability of such an event is 0.9 . Experimentally measured weight of high explosives $M_{\text {he }}$ needed for destruction of the aerial target are $[4,9]$ :

- $M_{\mathrm{he}} \in\langle 0.08,0.15\rangle \mathrm{kg}$, fighter,

- $M_{\mathrm{he}} \in\langle 0.20,0.30\rangle \mathrm{kg}$, tactical bomber,

- $M_{\text {he }} \in\langle 0.40,0.70\rangle \mathrm{kg}$, strategic bomber.

The number of projectiles $v$ that have to hit the target in order to destroy the target with probability of 0.9 is given by the following formula [4, 9]:

$$
v=\frac{M_{\mathrm{he}}}{m_{\mathrm{he}}},
$$

where $m_{\text {he }}$ - the weight of the high explosive in the projectile.

With regard to the above mentioned factors, the task of determination of the target destruction probability has to be solved not only according to the number of hits, but also according to the probability of target destruction $G(j)$ hit by $j$ projectiles. Then, the dependency of the probability $G(j)$ on the number of hits $j$ is called the Law of Target Destruction $[4,5]$. A realistic law of target destruction can be obtained only by shooting experiments [4]. However, for assessing combat effectiveness of the aircraft firing armament, the following theoretical laws of target destruction can be used: step law, and exponential law.

The step law is given by the following formula:

$$
G(j)=\left\{\begin{array}{l}
0 \text { for } j<v_{\mathrm{s}} \\
1 \text { for } j \geq v_{\mathrm{s}}
\end{array},\right.
$$

where $v_{\mathrm{s}}$ - the number of hits needed for a target destruction with a certain high destruction probability for the step law.

In this case, the number of hits $v_{\mathrm{s}}$ is equal to the minimal number of hits needed for the target destruction, $v_{\mathrm{s}}=v$. The step law fits very effectively when only one piece of effective ammunition is needed for target destruction (e.g. missile), then $v_{\mathrm{s}}=1[4,9]$.

The exponential law is given by the formula $[4,9]$

$$
G(j)=1-\left(1-\frac{1}{\omega}\right)^{j},
$$

where $\omega$ - the mean of hits needed to destroy the target.

The mean of hits is defined by the following formula $[4,9]$ 


$$
\omega=\sum_{j=0}^{\infty}[1-G(j)] .
$$

In this case, let's denote the number of hits needed to destroy the target with a certain high probability as $v_{\mathrm{e}}, v_{\mathrm{e}}=v$. Then, substituting $v_{\mathrm{e}}$ for $j$ in (18) gives:

$$
G\left(v_{\mathrm{e}}\right)=1-\left(1-\frac{1}{\omega}\right)^{v_{\mathrm{e}}}
$$

From the previous equation, the mean $\omega$ can be expressed as $[4,9]$

$$
\omega=\frac{1}{1-\sqrt[v_{\mathrm{e}}]{1-G\left(v_{\mathrm{e}}\right)}} .
$$

The best way to obtain the probability $G\left(v_{\mathrm{e}}\right)$ is by shooting experiments, or it can be selected - most commonly used is 0.9 in accordance with all the previously mentioned considerations [4]. Step law and exponential law are graphically represented in Fig. 4 and Fig. 5 for different values of $v_{\mathrm{s}}$ and $\omega$.

\subsection{Probability of Target Destruction}

Considering probability of the target hit and the law of destruction, the probability of target destruction is given by the following general formula $[4,9]$

$$
P_{\mathrm{D}}=\sum_{j=0}^{n} P_{\mathrm{I} j} G(j),
$$

where $P_{\mathrm{I} j}$ - the probability of a target hit for $j$ projectiles from $n$ fired projectiles,

$$
G(0)=0 \text {. }
$$

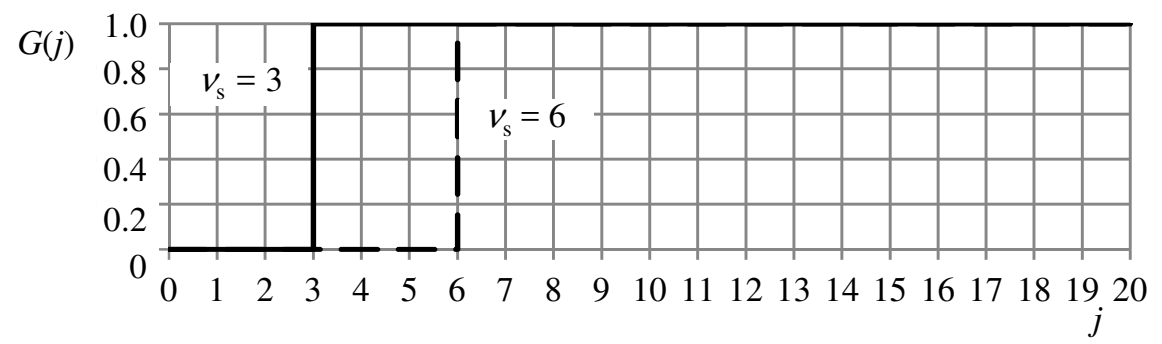

Fig. 4 Step law of target destruction

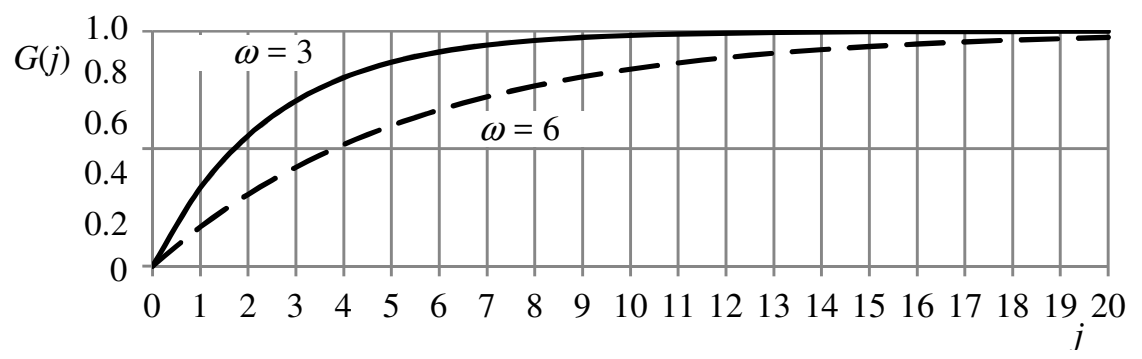

Fig. 5 Exponential law of target destruction 
Since the projectiles are launched from the cannon in series, the probability of target destruction is dependent on time. Character of this dependency becomes very important immediately after firing starts, as the cannons usually fire at aerial targets by relatively very short bursts. The main parameters and characteristics that the target destruction probability, for a cannon of a specific aircraft, depend on are: probability of the target hit, weapon rate of fire, weapon calibre, length of burst, target vulnerability, law of target destruction.

The probability of hitting the target depends on the projectile dispersion law and its parameters. When using aircraft cannons, it is assumed that the release of the individual projectiles in one burst is done under the same conditions. Then, the law of dispersion is the normal law of position distribution at the impact points [4, 9]. The probability of the target hit in the dispersion plane is then given by the size and form of the target, by accuracy of the aiming and by the probable errors.

The total weight of the projectiles (or weight of the bursting charges) released at the target can be expressed according to the cannon rate of fire, weapon calibre, and length of burst. With respect to the last, it is important whether the cannon achieves its nominal rate of fire right away with the first shot or at a certain delay after.

If the real law of target destruction is not available from the results of shooting experiments, an appropriate law shall be selected based on the analysis of a target vulnerability and the destructive effects of the ammunition. The parameters of the selected law have to be known for the calculation of the target destruction probability.

The results and the conclusions stated in the chapters 4.4. and 4.5. are valid under the assumption that the individual weapons have the same calibre, the same destructive effect of the projectiles, the same hit probability, and that all the weapons are firing at the same target.

\subsection{Step Law of Destruction}

If the probability of the target hits is constant for the individual projectiles while the step law of target destruction is applied, then the probability of the target destruction can be simply calculated based on the probability of combinations of target hits and misses for the individual projectiles. All the possible combinations of a certain number of projectiles hitting the target and missing the target have the same probability. As a result, the probability of a particular number of hits and misses is the product of the probability of a particular combination and its appropriate binominal coefficient.

If the probabilities of target hits by the individual projectiles differ and the step law of destruction is applied, the probabilities of every combination of target hits and misses have to be calculated separately. This task can be solved by using truth tables. We will not deal with this case, because it is not significant for our aim.

If the probability of the target hits $p$ for individual projectiles is the same, then the probability $P_{\mathrm{I} j}\left(A_{j}\right)$ of hitting the target by certain projectile number $j$ from the total projectile number $n$ fired at the target is expressed by the following formula: $[4,7,9]$

$$
P_{\mathrm{I} j}\left(A_{j}\right)=\left(\begin{array}{c}
n \\
j
\end{array}\right) p^{j}(1-p)^{n-j},
$$

where $A_{j}$ - the event where the target is hit only by $j$ projectiles from $n$ shots,

$j-$ the number of hits,

$n$ - the total number of shots,

$p$ - the probability of hitting the target by one projectile, 
$(1-p)$ - the probability of missing the target by one projectile,

$$
\left(\begin{array}{l}
n \\
j
\end{array}\right) \text { - the binomial coefficient. }
$$

The probability of target destruction can be expressed as the probability $P_{\mathrm{D}}\left(A \geq v_{\mathrm{s}}\right)$ of target hit by at least $v_{\mathrm{s}}$ projectiles. This probability is given by the following formula

$$
P_{\mathrm{D}}\left(A_{\geq v \mathrm{~s}}\right)=\sum_{j=v_{\mathrm{s}}}^{n}\left(\begin{array}{l}
n \\
j
\end{array}\right) p^{j}(1-p)^{n-j},
$$

where $A \geq v_{\mathrm{s}}$ - the occurence where the target is hit at least by $v_{\mathrm{s}}$ projectiles from $n$ shots.

It is a sum of all probabilities of target hits by a certain number of projectiles varying from $v_{\mathrm{s}}$ up to $n$. Probability $P_{\mathrm{ND}}\left(A_{<v_{\mathrm{s}}}\right)$ (probability of target survival) that the target is not destroyed by $n$ shots is

$$
P_{\mathrm{ND}}\left(A_{<v \mathrm{~s}}\right)=\sum_{j=0}^{v_{\mathrm{s}}-1}\left(\begin{array}{c}
n \\
j
\end{array}\right) p^{j}(1-p)^{n-j},
$$

where $A_{<v_{\mathrm{s}}}-$ the occurence where the target is hit by less than $v_{\mathrm{s}}$ projectiles.

Target destruction and target survival are complement occurrences. The relation between their probabilities is as follows

$$
P_{\mathrm{D}}\left(A_{\geq v \mathrm{~S}}\right)+P_{\mathrm{ND}}\left(A_{<v \mathrm{~S}}\right)=1 \text {. }
$$

When the number of projectiles needed for target destruction is less than half of the total number of shots, then the target destruction probability can be calculated by the following formula

$$
P_{\mathrm{D}}\left(A_{\geq v \mathrm{~s}}\right)=1-\sum_{j=0}^{v_{\mathrm{s}}-1}\left(\begin{array}{l}
n \\
j
\end{array}\right) p^{j}(1-p)^{n-j} .
$$

After expressing the binominal coefficient, the formula is as follows

$$
P_{\mathrm{D}}\left(A_{\geq \mathrm{vs}}\right)=1-\sum_{j=0}^{v_{\mathrm{s}}-1} \frac{n !}{j !(n-j) !} p^{j}(1-p)^{n-j} .
$$

If we want to express the probability of target destruction graphically as dependency on firing time and to compare the individual types of AAC mutually, we have to express firing time as dependency on the number of shots. For revolver and twin-barrelled cannons, and in accordance with (9) and (10), we can write

$$
\begin{aligned}
t_{\mathrm{R}} & =\frac{n}{k_{\mathrm{R}}}, \\
t_{\mathrm{T}} & =\frac{n}{k_{\mathrm{T}}} .
\end{aligned}
$$

The time interval needed to fire $n$ projectiles by a rotary cannon can be expressed from (11) and (12). For time period when $t \leq t_{\mathrm{a}}$, we get 


$$
t_{\mathrm{G} \leq t \mathrm{a}}=\sqrt{\frac{2 t_{\mathrm{a}} n}{k_{\mathrm{G}}}} .
$$

For time $t>t_{\mathrm{a}}$, we have

$$
t_{\mathrm{G}>t \mathrm{a}}=\frac{n}{k_{\mathrm{G}}}+\frac{t_{\mathrm{a}}}{2} .
$$

For given preconditions and individual types of cannons, the time dependences of the target destruction probabilities $P_{\mathrm{D}}(t)$ are depicted in Fig. 6. Individual depicted courses apply to nominal rates of fire calculated according to (5), (6) and (7), and to the following input quantities and parameters:

- the rate of fire $k_{\mathrm{cl}}$

- the number of barrels of rotary cannon $i_{\mathrm{b}}$ $800 \mathrm{~min}^{-1}$,

- the spin up time of rotary cannon $t_{\mathrm{a}}$ 5 ,

- the number of barrels of revolver cannon $0.3 \mathrm{~s}$,

- the number of chambers of revolver cannon 1 ,

- the probability of target hit by one projectile $p$ 5 ,

- the minimum number of hits needed for target destruction $v_{\mathrm{s}}$ 0.3

We assume the same calibre for all cannons, and therefore, every cannon also has the same minimum number of hits $v_{\mathrm{s}}$.

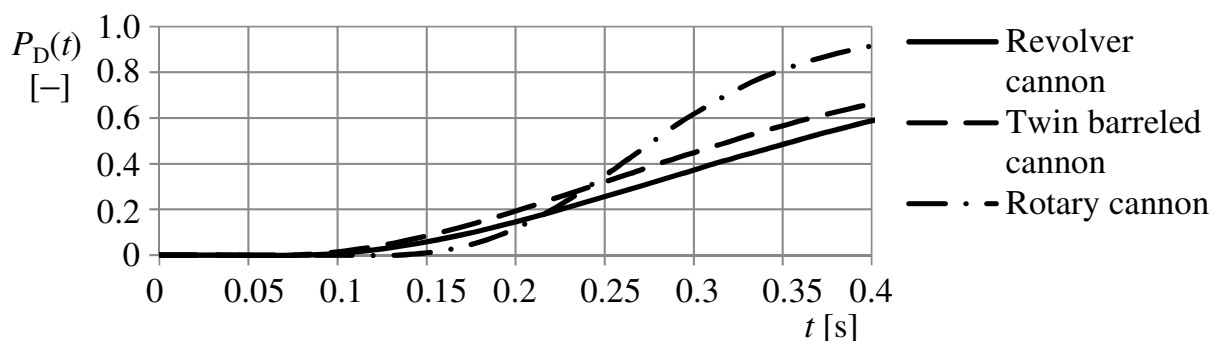

Fig. 6 Probability of target destruction - constant probability of target hits and step law of target destruction

\subsection{Exponential Law of Destruction}

When exponential law of target destruction applies, the following generating function can be used [5]

$$
\varphi_{\mathrm{n}}(z)=\prod_{i=1}^{n}\left(q_{\mathrm{i}}+p_{\mathrm{i}} z\right),
$$

where $p_{\mathrm{i}}$ - the probability of target hit by $i$ th projectile,

$q_{\mathrm{i}}-$ the probability of target miss by $i$ th projectile, $q_{\mathrm{i}}=1-p_{\mathrm{i}}$,

$z$ - the arbitrary parameter.

In line with the already introduced terms, see (22), we can write [5]

$$
\prod_{i=1}^{n}\left(q_{\mathrm{i}}+p_{\mathrm{i}} z\right)=\sum_{j=0}^{n} P_{\mathrm{Ij}}\left(A_{j}\right) z^{j},
$$

where $P_{\mathrm{Ij}}\left(A_{j}\right)$ - the probability of target hit by $j$ projectiles from $n$ fired projectiles. 
The following formula is derived for the probability $P_{\mathrm{ND}}$ of target survival $[4,9]$

$$
P_{\mathrm{ND}}=1-P_{\mathrm{D}}=\prod_{i=1}^{n}\left[q_{\mathrm{i}}+p_{\mathrm{i}} \overline{G(1)}\right]
$$

where $\overline{G(1)}=1-G(1)$,

$G(1)$ - the probability of target destruction for one hit.

By substituting 1 for $j$ into (18) and by modifying previous formula, we get general formula $[4,9]$

$$
P_{\mathrm{D}}=1-\prod_{i=1}^{n}\left(1-\frac{p_{\mathrm{i}}}{\omega}\right),
$$

which enables calculation of the target destruction probability when the probability of target hit by the individual projectiles changes during the burst. For a constant probability of hits, the formula (30) transforms into the following formula

$$
P_{\mathrm{D}}=1-\left(1-\frac{p}{\omega}\right)^{n} .
$$

Let's assume that the number of hits needed to destroy the target, with selected destruction probability, is three, $v_{\mathrm{e}}=3$. As mentioned above, the chosen destruction probability $G(3)=0.9$. Substituting these values into (20) we get $\omega=1.87$. For individual types of cannons with constant probability of hits, the time dependences of the target destruction probabilities $P_{\mathrm{D}}(t)$ are depicted in Fig. 7.

The graph courses in Fig. 7 are valid for the same weapon parameters and the same probability of target hits as in Fig. 6. From the provided figures, it is clear that the rotary cannon reaches the same probability of the target destruction as the twin barrelled and revolver cannons with a certain delay. This fact plays an important role when selecting a weapon for a specific aircraft.

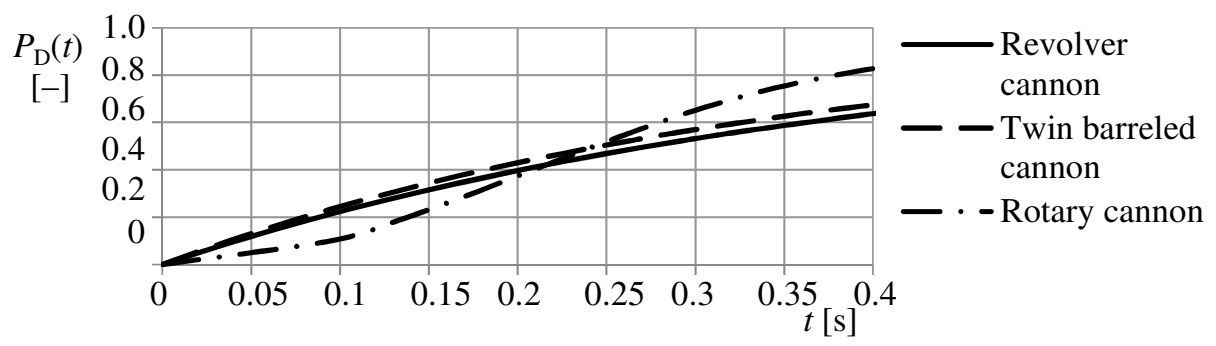

Fig. 7 Probability of target destruction - constant probability of target hit and exponential law of target destruction

\section{Probabilities of Target Destruction for Selected Cannons}

This chapter compares the probabilities of aerial target destruction for cannons used on the aircraft of the Czech Air Force and the M61A1 rotary cannon that belongs to the most frequently used AAC. The armament of the Czech Air Force Aircraft includes ZPL-20 and GSh-23 twin barrel cannons, and Bk-27 revolver cannon. 
Basic ammunition of ZPL-20 designed for the aerial target destruction are HEI (High-Explosive Incendiary) cartridges. Their bullets have a calibre of $20 \mathrm{~mm}$ and weight of $101 \mathrm{~g}$. Mass of HE material is $11 \mathrm{~g}[8,10]$.

The FHEI (Fragmentary HEI) and HEI cartridges are designed for GSh-23. The calibre is $23 \mathrm{~mm}$. The projectile mass of FHEI and HEI cartridges is $184 \mathrm{~g}$ and $188 \mathrm{~g}$, respectively [11]. Mass of the HE material is $19 \mathrm{~g}$ [2, 8]. The HEI cartridges of Bk-27 have calibre $27 \mathrm{~mm}$, the mass of projectile is $260 \mathrm{~g}$. The mass of HE filling is $39 \mathrm{~g} \mathrm{[2}$, $8,12]$.

Standard M61A1 cartridges are HEI. The projectile and HE filling mass are $109 \mathrm{~g}$ and $9 \mathrm{~g}$, respectively [2, 13]. The SAPHEI (Semi-Armor-Piercing High-Explosive Incendiary) cartridges can be used against aerial targets as well. Weight of the projectile and $\mathrm{HE}$ filling are $102 \mathrm{~g}$ and $10 \mathrm{~g}$, respectively [13].

Nominal fire rates are: $k_{\mathrm{T} 20}=2600 \mathrm{~min}^{-1}(\mathrm{ZPL}-20), k_{\mathrm{T} 23}=3400 \mathrm{~min}^{-1}(\mathrm{GSh}-23)$, $k_{\mathrm{R}}=1700 \mathrm{~min}^{-1}(\mathrm{Bk}-27), k_{\mathrm{G}}=6000 \mathrm{~min}^{-1}(\mathrm{M} 61 \mathrm{~A} 1)$ [2, 8]. If we assume that the M61A1 start-up is steady, we can estimate that the spin up time $t_{\mathrm{a}}=0.38 \mathrm{~s}$.

In order to assess the probability of target destruction for the selected weapons, we assume firing at a fighter type target which requires $0.08 \mathrm{~kg}$ of explosives to achieve destruction. The target was calculated as a rectangle with dimensions $a=10 \mathrm{~m}$ and $b=1 \mathrm{~m}$, see Fig. 3. Its vulnerability was expressed by both the step law and the exponential law of the target destruction. Probabilities of target hits for individual projectiles of a particular gun are the same. Probability values for the individual cannons and firing distances of $230 \mathrm{~m}$ and $800 \mathrm{~m}$, and probable errors are listed in Tab. 1.

Probable error values of GSh-23 are based on approximate figures mentioned in the discussion on the article in [15] but they meet the limit value specified in [16]. The values of Bk-27 probable errors were computed according to data for $\mathrm{KCA}$ revolver cannon [2].

Tab. 1 Probable errors and probabilities of hits

\begin{tabular}{|c|c|c|c|c|}
\hline \multirow{2}{*}{$\begin{array}{c}\text { Distance from } \\
\text { Target } \\
D[\mathrm{~m}]\end{array}$} & $\begin{array}{c}\text { ZPL-20 } \\
{[14]}\end{array}$ & $\begin{array}{c}\text { GSh-23 } \\
{[15,17]}\end{array}$ & $\begin{array}{c}\text { Bk-27 } \\
{[2]}\end{array}$ & $\begin{array}{c}\text { M61A1 } \\
{[17]}\end{array}$ \\
\cline { 2 - 5 } & 0.379 & 0.306 & 0.329 & 0.346 \\
\hline 230 & 1.318 & 1.064 & 1.146 & 1.203 \\
\hline 800 & \multicolumn{4}{|c|}{ For rectangular target: $a=10 \mathrm{~m}, b=1 \mathrm{~m}$} \\
\hline & ZPL-20 & GSh-23 & Bk-27 & M61A1 \\
\cline { 2 - 5 } & 0.925 & 0.974 & 0.956 & 0.949 \\
\hline 230 & 0.392 & 0.474 & 0.443 & 0.424 \\
\hline 800 & &
\end{tabular}

In line with (16), numbers of hits needed for destruction of the considered target, according to the individual laws, are as follows: $v_{\mathrm{sT2}}=v_{\mathrm{eT} 20} \approx 7$ (ZPL-20), $v_{\mathrm{sT} 23}=v_{\mathrm{eT} 23} \approx 4(\mathrm{GSh}-23), v_{\mathrm{sR}}=v_{\mathrm{eR}} \approx 2(\mathrm{Bk}-27)$, and $v_{\mathrm{sG}}=v_{\mathrm{eG}} \approx 9(\mathrm{M} 61 \mathrm{~A} 1)$.

For selected probability of the target destruction with practical certainty $G\left(v_{\mathrm{e}}\right)=0.9$, the corresponding means of hits needed to destroy the target are as follows, see $(20): \omega_{\text {Г20 }} \approx 3.57(\mathrm{ZPL}-20), \omega_{\mathrm{\Gamma} 23} \approx 2.28(\mathrm{GSh}-23), \omega_{\mathrm{R}} \approx 1.46(\mathrm{Bk}-27), \omega_{\mathrm{G}} \approx 4.43$ (M61A1). 
Time dependences of the target destruction probabilities for individual cannons using both laws are graphically plotted in Fig. 8 and Fig 9.

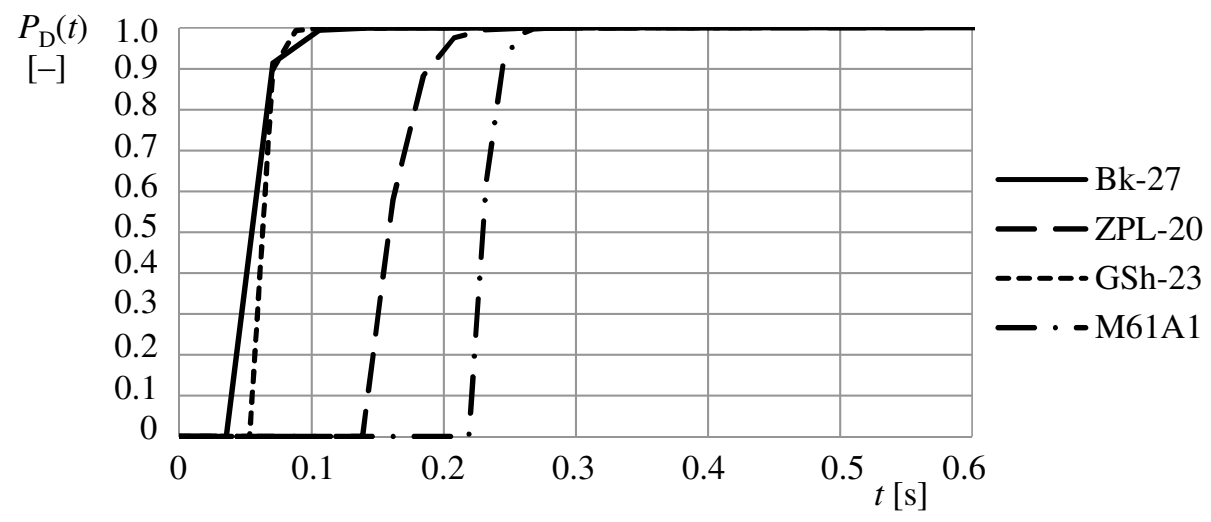

a) Distance of target $D=230 \mathrm{~m}$

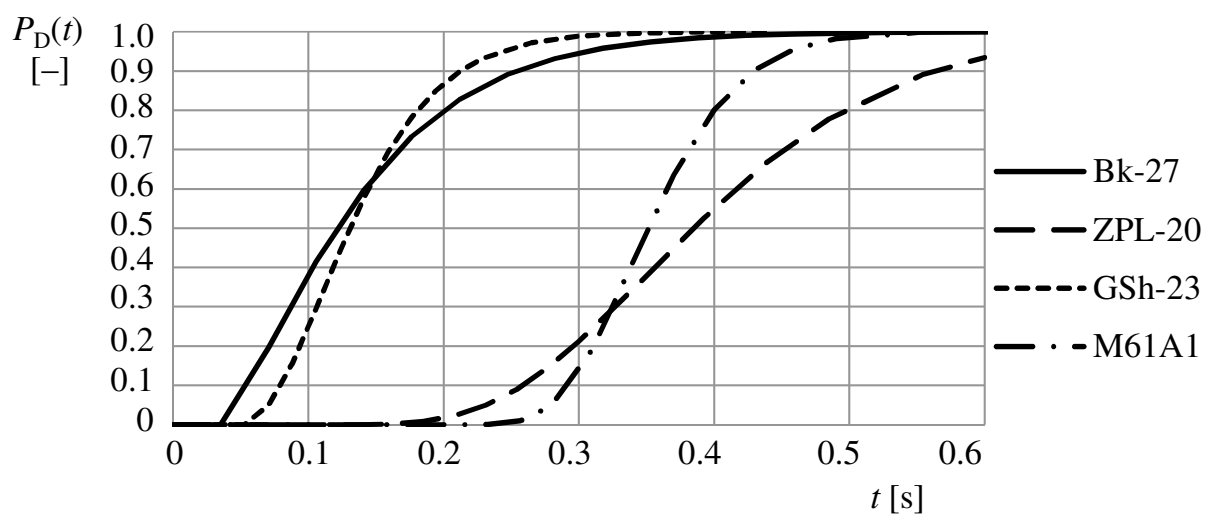

b) Distance of target $D=800 \mathrm{~m}$

Fig. 8 Probability of target destruction for selected cannons - step law of destruction

\section{Conclusion}

From Fig. 8 and Fig. 9, it is apparent that the target destruction probabilities differ according to the used law of destruction. Thus, for precise and credible analysis of the AAC performance, it is necessary to use precisely defined specific target's destruction laws for the individual AAC. Nevertheless, we can make several conclusions from the acquired results.

The probability of target destruction for all the weapons with the target distance of $800 \mathrm{~m}$ is lower than the probability with target distance of $230 \mathrm{~m}$. The reason is a decrease in the target hit probability as with increasing target distance the dispersion pattern is increasing. As a result, time dependencies of the destruction probability are steeper for smaller distances. 


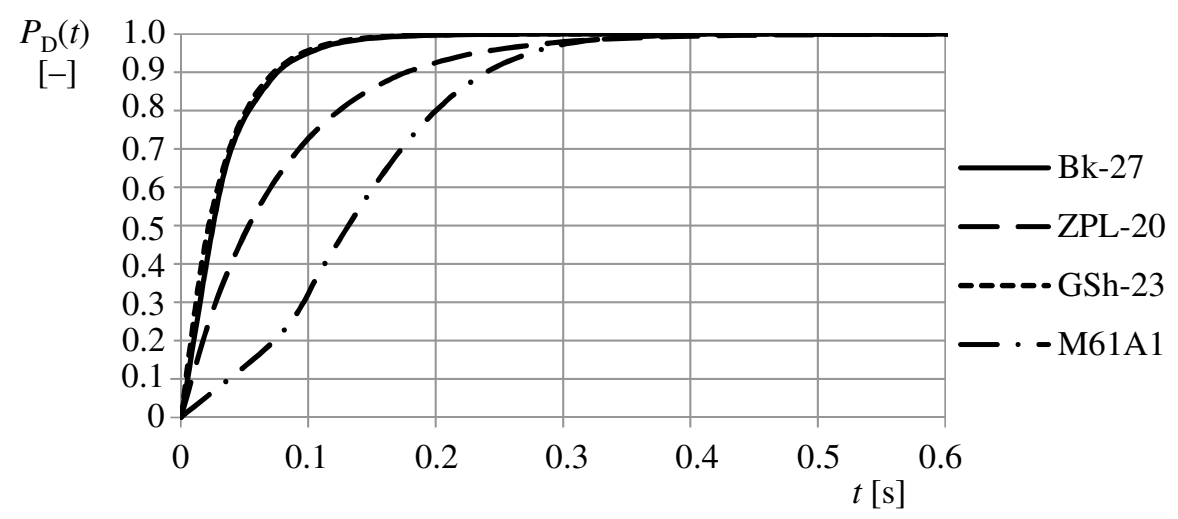

a) Distance of target $D=230 \mathrm{~m}$

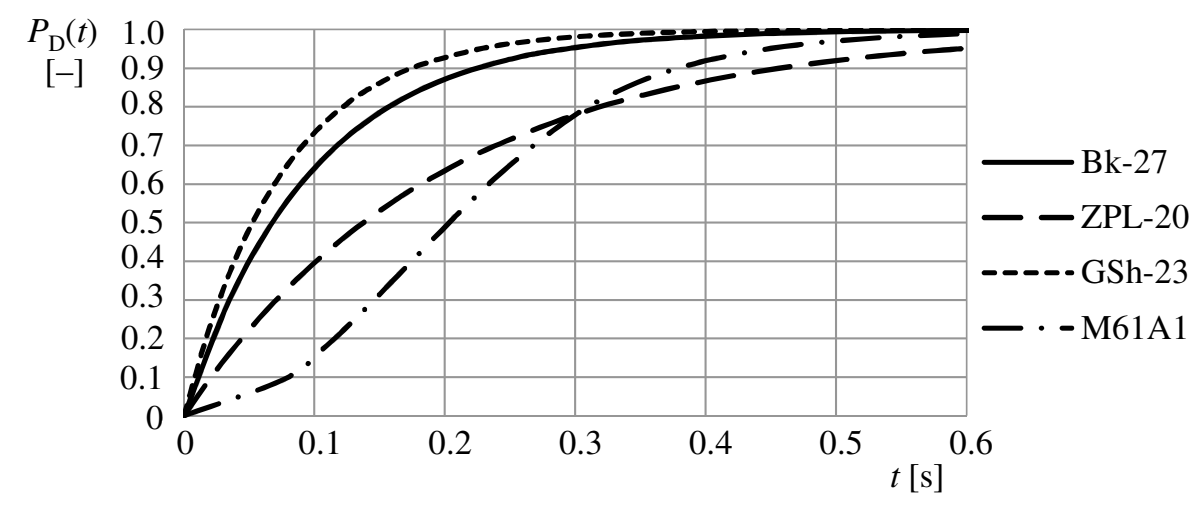

b) Distance of target $D=800 \mathrm{~m}$

Fig. 9 Probability of target destruction for selected cannons - exponential law of destruction

In terms of destruction probability, there is no significant difference between the Bk-27 and GSh-23 guns. Graphs show that each gun has advantage in different time periods. Both guns reach the destruction probability with practical certainty of 0.9 about $0.07 \mathrm{~s}$ for the distance of $230 \mathrm{~m}$ and $0.23 \mathrm{~s}$ (step law) and $0.20 \mathrm{~s}$ (exponential law) for the distance of $800 \mathrm{~m}$. Bk-27 has bigger calibre, thus the projectile number, needed for achieving this probability, is smaller. The ZPL-20 and M61A1 guns are obviously less powerful during initial period of shooting. In the comparison with Bk-27 and GSh-23, they achieve the destruction probability of 0.9 during more than double time.

As the number of cartridges carried by different aircraft is relatively small, durations of bursts are limited. It is 20 or 50 shots for the L-159 aircraft for example. The corresponding durations of these bursts are $0.46 \mathrm{~s}$ and $1.15 \mathrm{~s}$. Figures show that for both a step law and an exponential law, the probabilities of destruction are practically the same for all guns, for both selected distances in mentioned times.

For the above reasons, the Bk-27 and GSh-23 appear as the best cannons. However, the selection of weapon for a specific aircraft depends on other parameters such as weight, dimensions of the cannon as well as its ammunition, number of carried cartridges, time of projectile flight to the target, way of primer ignition, type of firing 
control system and gunsight, type of firing post, service life and so on [2]. If we consider this complex approach, we can state that the individual Czech Air Force aircraft are armed with appropriate cannons.

\section{Acknowledgement}

The work presented in this article has been supported by the Czech Republic Ministry of Defence - University of Defence development program "Research of sensor and control systems to achieve battlefield information superiority".

\section{References}

[1] POPELÍNSKÝ, L. and V. KODEŠ. Firing and Rocket Armament of Aircraft (in Czech). Praha: Naše vojsko. 1997. 288 p. ISBN 80-206-0531-2.

[2] WILliAMS, A.G. and GUSTIN, E. Flying Guns. The Modern Era. The Crowood Press: Ramsbury, 2004. 240 p. ISBN 1-86126-655-3

[3] BALLA, J. and MACH, R. Kinematics and Dynamics of Gatling Weapons. Advances in Military Technology, 2007, vol. 2, no. 2, p. 121-133. ISSN 1802-2308.

[4] MOLL, V., NĚMEČEK, J. and POLÁŠEK, M. Weapon Control Systems of Aircraft (in Czech). Brno: University of Defence. 2008. 105 p. ISBN 978-80-7231609-0.

[5] VENTCEL'OVÁ, J.S. Theory of Probability (in Slovak). First edition.. Bratislava: ALFA, 1973. 524 p.

[6] MAZOCH, J. Aerial Fire, part I (in Czech). Brno: Military Academy of Antonín Zápotocký, 1962. 218 p.

[7] STRICLAND, J.S. Fundamentals of Combat Modeling [on line]. Lulu, 2011 [cited 2015-7-20]. ISBN 978-1-257-00583-3. Available from: <https://books. google.cz/books?id=rO_BAwAAQBAJ\&printsec=frontcover\&vq=probability + of + target + destruction $\& \mathrm{hl}=\mathrm{cs} \# \mathrm{v}=$ onepage $\& \mathrm{q}=$ probability $\% 20 \mathrm{of} \% 20$ target $\% 20$ destruction $\& \mathrm{f}=$ false $>$.

[8] JANOŠEK, M. and SVOBODA, A. Performance of Aircraft Cannons in Terms of their Employment in Air Combat. Advances in Military Technology, 2007, vol. 2, no. 2, p. 33-44. ISSN 1802-2308.

[9] MAZOCH, J. Aerial Fire, part V (in Czech). Brno: Military Academy of Antonín Zápotocký, 1976. 103 p.

[10] PLAMEN AIRCRAFT GUN POD PL-20. ZVI [on line]: Praha. [cited 2015-7-10]. Available from: <http://www.zvi.cz/vyrobni-program/plamen.html>

[11] ŠUCHA, P. Grjazev - Shipunov GSh-23L. LIETADLA.COM [on line]. Updated 10 April 2015 [cited 2015-7-10]. Available from: <http://www.lietadla.com/ vyzbroj/gs-23.htm>.

[12] Mauser Bk-27. Wikipedia [on line]. Wikimedia Foundation. Updated 23 April 2015. [cited 2015-7-10]. Available from: <https://en.wikipedia.org/wiki/Mauser -BK-27>.

[13] M61 Vulcan. Wikipedia [on line]. Wikimedia Foundation. Updated 14 July 2015. [cited 2015-7-10]. Available from: <https://en.wikipedia.org/wiki/M61_Vulcan>. 
[14] SMILEK, P. The Verification of Pl-20 complex in Operation (in Czech). (The Report of the Trial on the Producer). Praha: ZVI, 2005.

[15] The Netherlands Published the Content of Boeing Crew Conversations. (in Czech). AC24.cz [on line]. AC24, s.r.o., (C) 2011-2016. Updated 9 September 2014. [cited 2016-12-21]. Available from: <http://www.ac24.cz/zpravy-ze-sveta/ 4780-nizozemsko-zverejnilo-obsah-rozhovoru-posadky-boeingu>.

[16] MATVEYEV, A.I. and SAZONOV, D.V. Aircraft firing posts (in Russian). Samara: Samara State Aerospace University, 2011. 69 p.

[17] HAVELKA, R. Principle Gatling (in Czech). Valka.cz [on line]. Nelahozeves: Radek Havelka, 1998-2015 [cited 2015-7-10]. Available from: <https://www. valka.cz/1048-Princip-Gatling-a-letecke-rotacni-kanony>. 